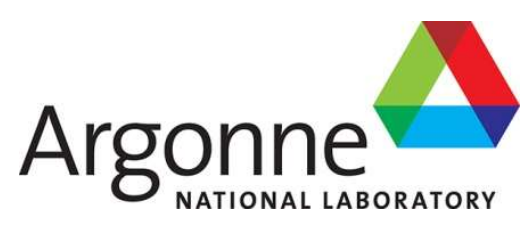

\title{
The Precision of Product Consistency Tests with Reference Glasses ARM-1 and SRM 623
}

Chemical and Fuel Cycle Technologies Division 


\section{About Argonne National Laboratory}

Argonne is a U.S. Department of Energy laboratory managed by UChicago Argonne, LLC under contract DE-AC02-06CH11357. The Laboratory's main facility is outside Chicago, at 9700 South Cass Avenue, Argonne, Illinois 60439. For information about Argonne

and its pioneering science and technology programs, see www.anl.gov.

\section{DOCUMENT AVAILABILITY}

Online Access: U.S. Department of Energy (DOE) reports produced after 1991 and a growing number of pre-1991 documents are available free at OSTI.GOV (http://www.osti.gov/), a service of the US Dept. of Energy's Office of Scientific and Technical Information.

Reports not in digital format may be purchased by the public from the National Technical Information Service (NTIS):

U.S. Department of Commerce

National Technical Information Service

5301 Shawnee Rd

Alexandria, VA 22312

www.ntis.gov

Phone: (800) 553-NTIS (6847) or (703) 605-6000

Fax: (703) 605-6900

Email:orders@ntis.gov

Reports not in digital format are available to DOE and DOE contractors from the Office of Scientific and Technical Information (OSTI):

U.S. Department of Energy

Office of Scientific and Technical Information

P.O. Box 62

Oak Ridge, TN 37831-0062

www.osti.gov

Phone: (865) 576-8401

Fax: (865) 576-5728

Email: reports@osti.gov

\section{Disclaimer}

This report was prepared as an account of work sponsored by an agency of the United States Government. Neither the United States Government nor any agency thereof, nor UChicago Argonne, LLC, nor any of their employees or officers, makes any warranty, express or implied, or assumes any legal liability or responsibility for the accuracy, completeness, or usefulness of any information, apparatus, product, or process disclosed, or represents that its use would not infringe privately owned rights. Reference herein to any specific commercial product, process, or service by trade name, trademark, manufacturer, or otherwise, does not necessarily constitute or imply its endorsement, recommendation, or favoring by the United States Government or any agency thereof. The views and opinions of document authors expressed herein do not necessarily state or reflect those of the United States Government or any agency thereof, Argonne National Laboratory, or UChicago Argonne, LLC. 

Glasses ARM-1 and SRM 623

prepared by

W.L. Ebert

Chemical and Fuel Cycle Technologies Division, Argonne National Laboratory

December 2019 


\section{CONTENTS}

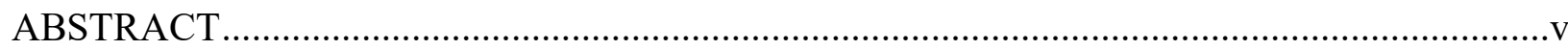

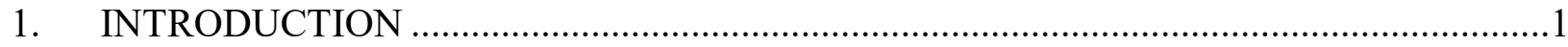

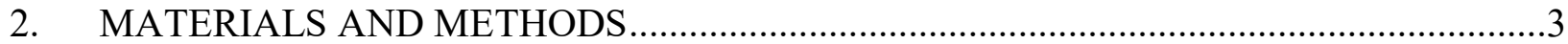

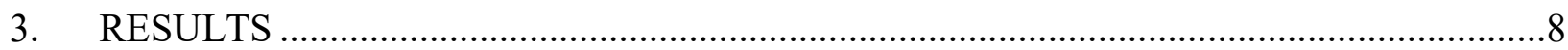

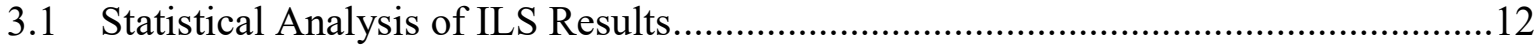

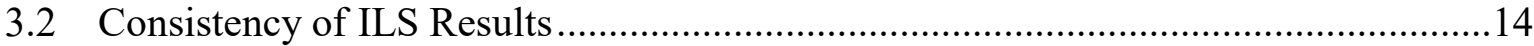

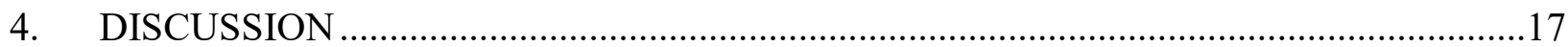

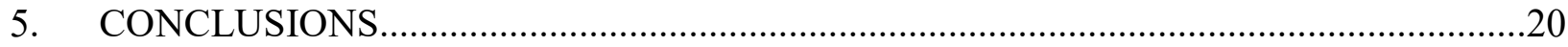

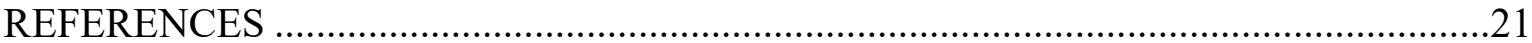




\section{FIGURES}

1. Photomicrographs of $-100+200$ mesh size glass prepared by dry-sieving (a) ARM-1

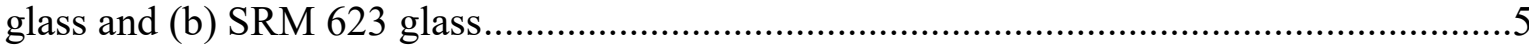

2. Measured particle size distributions of ARM-1 and SRM 623 glasses in $-100+200$

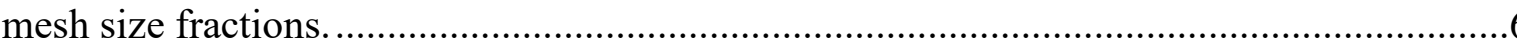

3. Normal distribution compared to Microtrac results for $-100+200$ mesh size fraction of dry-sieved ARM-1 glass and calculated distribution of areas for spherical particles............7

4. Individual $N L(B), N L(N a)$, and $N L(S i)$ values for tests with (a) ARM-1 glass and (b)

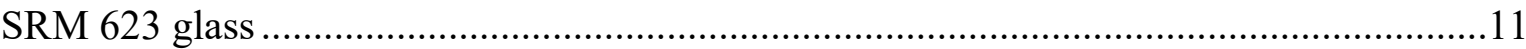

5. Mean values of $N L(B), N L(N a)$, and $N L(S i)$ for PCT-A tests with ARM-1 and SRM 623 glasses

6. Values of (a) $h$-statistic and (b) $k$-statistic for PCT-A tests with ARM-1 and SRM 623 glasses .16

7. Consensus mean and reproducibility standard deviation values from ILS conducted using glass with and without fines 


\section{TABLES}

1. Compositions of ARM-1 and SRM 623 glasses, mass fraction.......................................4

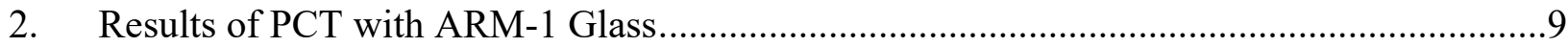

3. Results of PCT with SRM 623 Glass............................................................................ 10

4. Summary of Precision Statistics for PCT-A Tests .............................................................13

5. Summary of $h$-Consistency and $k$-Consistency Values .................................................15

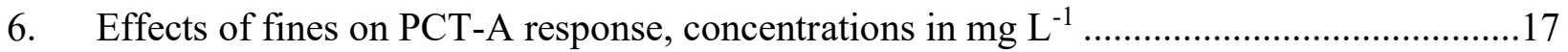




\title{
THE PRECISION OF PRODUCT CONSISTENCY TESTS WITH REFERENCE GLASSES ARM-1 AND SRM 623
}

\begin{abstract}
An interlaboratory study (ILS) was conducted with five participants to measure the precision with which the ASTM C1285 product consistency test method A (PCT-A) can be performed using samples of reference glass ARM-1 or SRM 623 from which fines were removed and with test parameter values near the centers of ranges specified in the procedure. The results are used to quantify the repeatability and reproducibility of test execution and provide reference test values to which tests conducted with other parameter values can be compared. The results of this ILS can be used to assess the precision and accuracy of tests conducted with these glasses at other laboratories and by different operators, to quantify the effects of individual test parameter values on the test response, and to quantify uncertainties in glass dissolution rates derived from tests conducted for different durations.
\end{abstract}




\section{INTRODUCTION}

The ASTM-International standard method C1285 Product Consistency Test (PCT) is used routinely to study the chemical durability and corrosion behaviors of nuclear waste glasses. The PCT is a simple test to perform: measured masses of crushed glass and leachant are sealed in a test vessel that is placed in a controlled oven without agitation. The amounts of key glass constituents released into solution during the test are used to characterize the dissolution behavior and quantify the chemical durability of the glass. The ASTM C1285 standard includes methods PCT-A and PCT-B that are distinguished by the values of the test parameter values and conditions and are used for different purposes: PCT-A tests are conducted under specific conditions to directly compare the test responses of different materials, whereas PCT-B tests can be conducted to study the dissolution behavior of a material under a range of conditions. The PCT method A (PCT-A) was developed specifically "to evaluate whether the chemical durability and elemental release characteristics of nuclear, hazardous, and mixed glass waste forms have been consistently controlled during production" [1]. The ranges of acceptable test parameter values specified for PCT-A were selected to facilitate the testing highly radioactive waste glass in a hot cell and adequately distinguish the responses of different glass compositions within a short test period, but may not provide the optimum test precision. Many PCT-B tests have been conducted using different test parameter values to develop and parameterize waste glass degradation models.

The uncertainties in the PCT response can be attributed to three aspects of the test: characteristics of the crushed glass, test execution, and analysis of the test solution. Important characteristics of the crushed glass are the distributions of particle sizes, shapes, fracture edges, and the amounts of fine particles generated during crushing that adhere to the glass particles used in the PCT. Uncertainties contributing to the test response that arise from test execution include the following: the weighed masses of water and glass when the test is assembled; the amounts of contaminants in the vessel and water; the temperature attained by the vessel contents during the test and the reaction time at that temperature; uncertainties in the weighed mass of water lost during the test due to vessel leakage, the mass of test solution to be analyzed, the mass of water added for dilution, and (typically) the mass of nitric acid that is added to stabilize the test solution either at the end of the test or by the analyst prior to solution analysis. Analytical uncertainties include calibration of the balances and the instrument(s) used to analyze the test solution. The precision with which PCTs can be conducted affects the capacity of Method A tests to distinguish the test responses of different glasses and the accuracy with which Method B tests can quantify the effects of test variables on the dissolution kinetics. Because the glass preparation, test execution steps, solution analyses, and calculations are the same for PCT-A and PCT-B, the test precision is the same for both methods. Furthermore, the precision determined for execution of PCT-A can be used to assess the effects of particular test variables on the PCT-B response.

An interlaboratory study (ILS) was conducted to measure the precision with which PCT can be performed with reference glasses ARM-1 and SRM 623 that have been thoroughly washed to remove fines within the ranges of parameter values specified for Method A. The inter- and intralaboratory precisions determined based on the results of triplicate tests conducted by five participating laboratories are presented in this paper. The measured precisions include variance in test execution and solution analysis, but exclude variance due to sample preparation.

The ILS measured the precision with which PCTs can be conducted by a researcher using properly prepared samples of two reference glasses that are free of adhering fines. When first developed in the 1980's, PCT-A tests were conducted using crushed and sized glass from which the fine particles generated during the crushing and sieving operations had not been removed. The procedure now calls for removing fines by repeatedly rinsing the sized glass in water (and/or a non-aqueous solvent) with agitation or by wet-sieving to isolate the desired size fraction (ASTM 2015a). This is because dissolution 
of the fines can dominate the test response and lead to erroneous conclusions regarding glass durability. 1 The amounts of fine particles present in individual samples are not known and probably vary with the glasses being tested and aspects of sample preparation. Accurate dissolution rates cannot be derived from the results of either PCT-A or PCT-B tests conducted with glass samples that include fines due to the dominant and unquantifiable effect dissolution of those fines has on the solution composition. The dissolution of different amounts of fines in different tests will overwhelm differences in the responses of tests with different glasses or different test conditions. The present study was conducted with two readily available and commonly used reference glasses-ARM-1 and SRM 623 - that had been prepared by dry sieving and thorough washing to completely remove fines. The same glasses were used in an ILS of the PCT-A method performed in ca. 1989 using crushed glasses from which the fines had not been removed prior to testing [5]. The results of the two studies indicate the effect of fines on the test responses and test precision.

Glass is prepared for testing by mechanically crushing large pieces and sieving the small pieces to isolate particles within the desired size fraction that passes through the upper bounding mesh size but does not pass through the lower bounding mesh size. The PCT-A defines the bounding mesh sizes, but does not require analysis of the size distribution of the separated particles. Although tests are assembled based on the masses of the glass sample and added leachant, the test response is sensitive to the surface area of glass that is available rather than the mass. The relationship between the surface area and mass depends on the range of particle sizes and particle shapes present within the sieved size fraction and the density of the glass. The crushing, sieving, and washing operations can all introduce bias to the particle size distribution. The sensitivity of the test response to the particle size distribution contributes to the variance in PCT responses measured for different batches of glass prepared in the same or different laboratories. Therefore, the crushed and sized glass used in tests conducted by all participants in the ILS was provided from a common stock prepared at Argonne to exclude the contribution of sample preparation from the test precision measured in the ILS. The ILS results provide the ranges of test responses that can be expected in PCT-A tests conducted with these reference glasses and used to demonstrate proper test performance. This may be to confirm the techniques of a new user, evaluate the efficiency of sample preparation, track the long-term consistency of tests conducted in a particular laboratory (e.g., by control charting), etc. The test precision also indicates the statistical limits to which PCT-A and PCT-B test responses can be distinguished.

Each glass was crushed and dry-sieved to isolate the $-100+200$ mesh size fraction. Glasses were meticulously cleaned of adhering fine particles to the extent that fines could not be detected by using a scanning electron microscope (SEM). Beside the presence of fines and variances in the particle size distributions, imprecision in the test responses may be due to uncertainties in the mass measurements, water loss from the vessel during the test, inaccuracies in the oven temperature, variance in the test duration, and uncertainties in the solution analysis. The PCT-A specifies the acceptable ranges in the masses, temperature, and duration. These ranges were applied in the ILS such that the combined effects of these test parameters on the test response are included in the measured precision. The precision of all test responses include the inherent analytical uncertainties in mass measurements and solution analysis; these are lumped with the overall precision of the test response and not measured directly.

\footnotetext{
1 The PCT method was designed to compare the dissolution kinetics under controlled conditions that provided test solutions with measurable concentrations of soluble glass constituents within a short test duration but remained significantly undersaturated. Fines facilitate the approach to saturation, but prevent accurate determination of the dissolution kinetics on a glass surface area basis.
} 
The prior experience of each participant in conducting PCT-A tests ranged from none to extensive, and the impact of experience on the results was an intended aspect of the study. The participating laboratories and points of contact were:

Argonne National Laboratory, Lemont, IL, USA

William Ebert

Japan Atomic Energy Agency, Ibaraki, Japan

National Nuclear Laboratory, Sellafield, UK

Seiichiro Mitsui

Pacific Northwest National Laboratory, Richland, WA, USA

Mike Harrison

Savannah River National Laboratory, Aiken, SC, USA

Michael Schweiger

Charles Crawford 


\section{MATERIALS AND METHODS}

The ARM-1 and SRM 623 glasses used in the PCT-A tests in the ILS and testing parameter effects study were provided by Pacific Northwest National Laboratory and Savannah River National Laboratory, respectively. The glass compositions are provided in Table 1. The ILS was conducted using sized glass that was prepared at ANL by crushing in a laboratory mill with a tungsten carbide blade and isolating the fraction that passed through a 100 mesh sieve but was retained by a 200 mesh sieve. These sieves are made with stainless steel mesh and have square openings of $150 \mu \mathrm{m}$ and $75 \mu \mathrm{m}$, respectively. Large pieces of glass were placed in nested plastic bags and broken with a hammer to generate pieces less than about $1 \mathrm{~cm}$ that would fit in the mill. Approximately $20 \mathrm{-g}$ batches of glass were crushed by pulsing the mill several times for intervals of a few seconds to generate smaller particles without generating excessive amounts of fine material. Small batches of crushed glass were passed through a nested set of 80-, 100-, and 200-mesh size sieves using a mechanical sifter. The glass retained by the 80 and 100 mesh sieves was placed back in the mill with a few large pieces and the mixture was milled again. The $-100+200$ mesh size fractions generated by sieving each batch were combined and the glass passing through the 200 mesh sieve was discarded.

Table 1. Compositions of ARM-1 and SRM 623 glasses, mass fraction

\begin{tabular}{lccccc}
\hline & \multicolumn{2}{c}{ Oxide } & & \multicolumn{2}{c}{ Elemental } \\
\hline & ARM-1 & SRM 623 & & ARM-1 & SRM 623 \\
\hline $\mathrm{Al}_{2} \mathrm{O}_{3}$ & 0.0559 & 0.063 & $\mathrm{Al}$ & 0.0296 & 0.0333 \\
$\mathrm{~B}_{2} \mathrm{O}_{3}$ & 0.113 & 0.107 & $\mathrm{~B}$ & 0.0351 & 0.0332 \\
$\mathrm{BaO}$ & 0.0066 & 0.022 & $\mathrm{Ba}$ & 0.00591 & 0.0197 \\
$\mathrm{CaO}$ & 0.0224 & 0.007 & $\mathrm{Ca}$ & 0.0160 & 0.00500 \\
$\mathrm{CeO}_{2}$ & 0.0151 & - & $\mathrm{Ce}$ & 0.0123 & - \\
$\mathrm{Cs}_{2} \mathrm{O}$ & 0.0117 & - & $\mathrm{Cs}$ & 0.0110 & - \\
$\mathrm{K}_{2} \mathrm{O}$ & - & 0.006 & $\mathrm{~K}$ & - & 0.00498 \\
$\mathrm{Li}_{2} \mathrm{O}$ & 0.0508 & - & $\mathrm{Li}$ & 0.0236 & - \\
$\mathrm{MoO}_{3}$ & 0.0166 & - & $\mathrm{Mo}$ & 0.0111 & - \\
$\mathrm{Na}_{2} \mathrm{O}$ & 0.0966 & 0.064 & $\mathrm{Na}$ & 0.0717 & 0.0475 \\
$\mathrm{Nd}_{2} \mathrm{O}_{3}$ & 0.0596 & - & $\mathrm{Nd}$ & 0.0511 & - \\
$\mathrm{P}_{2} \mathrm{O}_{5}$ & 0.0065 & - & $\mathrm{P}$ & 0.00284 & - \\
$\mathrm{SiO}_{2}$ & 0.465 & 0.73 & $\mathrm{Si}$ & 0.217 & 0.341 \\
$\mathrm{SrO}$ & 0.0045 & - & $\mathrm{Sr}$ & 0.00380 & - \\
$\mathrm{TiO}_{2}$ & 0.0321 & - & $\mathrm{Ti}$ & 0.0192 & - \\
$\mathrm{ZnO}$ & 0.0146 & - & $\mathrm{Zn}$ & 0.0117 & - \\
$\mathrm{ZrO}_{2}$ & 0.018 & - & $\mathrm{Zr}$ & 0.0133 & - \\
\hline
\end{tabular}

The adhering fines were removed by placing a portion (about $20 \mathrm{~g}$ ) of the sized glass in a 100 -mL beaker and adding a volume of distilled water that was about 5-times the volume of glass. The mixture was gently swirled to agitate and suspend the fine particles in the water. The larger particles were allowed to settle for a few seconds, and then most of the water was decanted to remove fines that remained suspended. This was repeated until no suspended fines could be seen with the unaided eye, which typically required about 12 repetitions for each portion of sized glass. The glass was then immersed in distilled water and ultrasonicated for several minutes to dislodge the remaining fines. After a short settling 
time of a few seconds, the water was decanted and replaced with fresh demineralized water and ultrasonicated again. The process was repeated until no suspended fines could be seen. No effort was made to quantify the exact settling time or the efficiency of decanting, which may have impacted the fraction of particles slightly larger than the 200 mesh lower size limit that were lost in the decanted solution. However, the researcher who prepared the glass (WLE) has prepared glasses for PCTs for more than 25 years and the glass prepared for testing is considered to represent the typical efficiency of the decanting method. Finally, the washed glass was dried overnight in an oven at $90{ }^{\circ} \mathrm{C}$. A few particles of the dried glass were removed and inspected for the presence of fines by using a scanning electron microscope (SEM). If fines were seen, the glass was repeatedly ultrasonicated and decanted until no fines were detected on the particles by SEM.

Figures 1a and 1b show SEM photomicrographs of glass particles prepared for use in the ILS by drysieving and washing. A few "divots" that were generated during crushing can be seen on some particles. These and the sharp edges formed when the glass fractured are unavoidable consequences of crushing. These features probably have a small effect on the initial dissolution rate of the glass, but are insignificant relative to the amount of glass that dissolves during a PCT-A. About $50 \mathrm{~g}$ of each glass was prepared for use in tests to be conducted by 5 participants in the ILS. About $8 \mathrm{~g}$ of each glass were placed in scintillation vials and shipped to each participant.

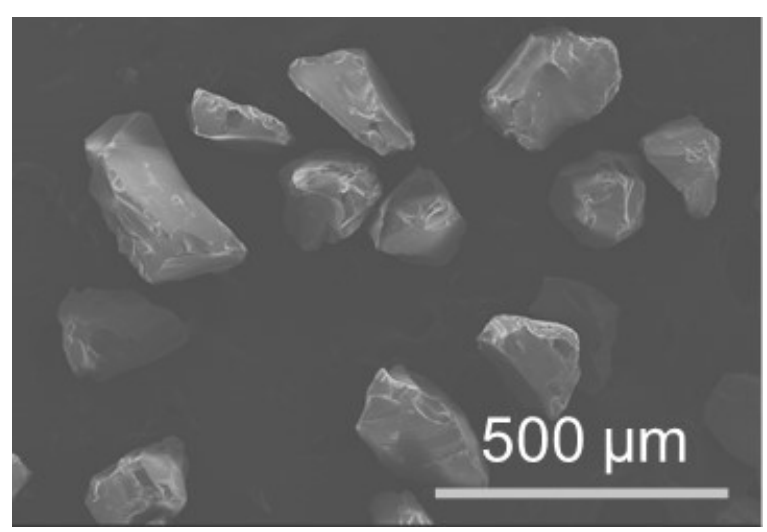

(a)

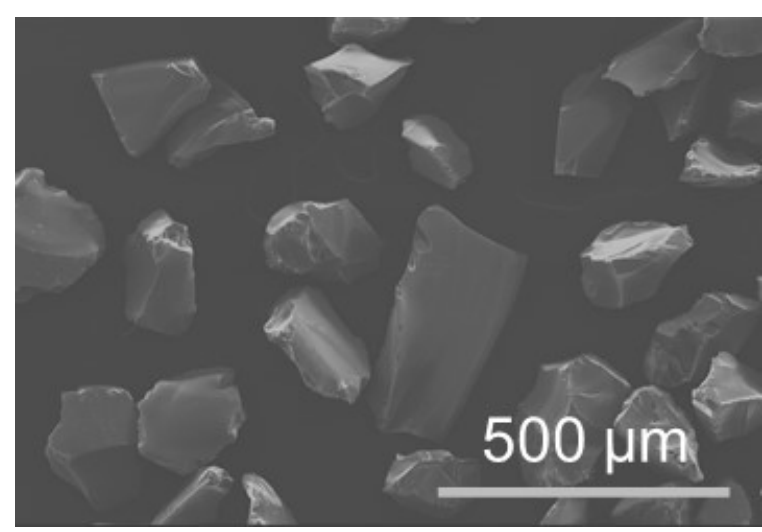

(b)

Figure 1. Photomicrographs of $-100+200$ mesh size glass prepared by dry-sieving (a) ARM-1 glass and (b) SRM 623 glass.

The particle size distribution was measured at Savannah River National Laboratory by using a Microtrac particle analyzer. The analyzer provides results in terms of diameter, area, and volume; only the results in terms of diameter were used. This is because the specific surface area in ASTM C1285 is calculated based on the average sieve opening size and density of the glass. The surface area availible for reaction in a PCT is required to derive the glass dissolution rate from the measured concentrations of glass constituents in the solution. ${ }^{2}$ The PCT procedure recommends calculating the glass surface area available in the test by representing the particles as a simple geometric shape having one dimension equal to the arithmetic average of the sieve openings, such as the diameter of a spherical particle or edge of a cubic particle. The accuracy of that approach has been verified by comparing the kinetic reaction rates of monolithic samples

2 The use of PCT-A for evaluating waste glass acceptability is based on the compositions of the solution and glass, and does not require estimation of the surface area. 
of known area with that measured for crushed and sized glass [2,3]. The consistency of PCT responses is strongly affected by the consistency of the surface area that is availible for the glass samples used in each test; that depends on a consistent distribution of particle sizes in the prepared glass and the absence of fines. For example, a $1-\mathrm{g}$ sample of glass having a density of $2.6 \mathrm{~g} \mathrm{~cm}^{-3}$ in the $-100+200$ mesh fraction used in a typical PCT-A provides about 65,000 particles. The variation in particle size distributions of several 1-g samples taken from a common source is expected to be negligible. However, the crushing, sieving, and washing methods with which each batch of glass is prepared for testing may affect the particle size distributions in different source batches.

The measured particle size distributions in the $-100+200$ mesh fractions of dry-sieved ARM- 1 and SRM 623 glasses are shown in Figure 2. Note that these measurements were made with approximately 0.1 -g samples of crushed glass. Both glasses have nearly normal size distributions with about the same mean values and widths at half-height, but the distribution of SRM 623 glass is noticably shifted to slightly smaller diameters than the ARM-1 glass. Both distributions are truncated at the $60-\mu \mathrm{m}$ analytical limit of the instrument.

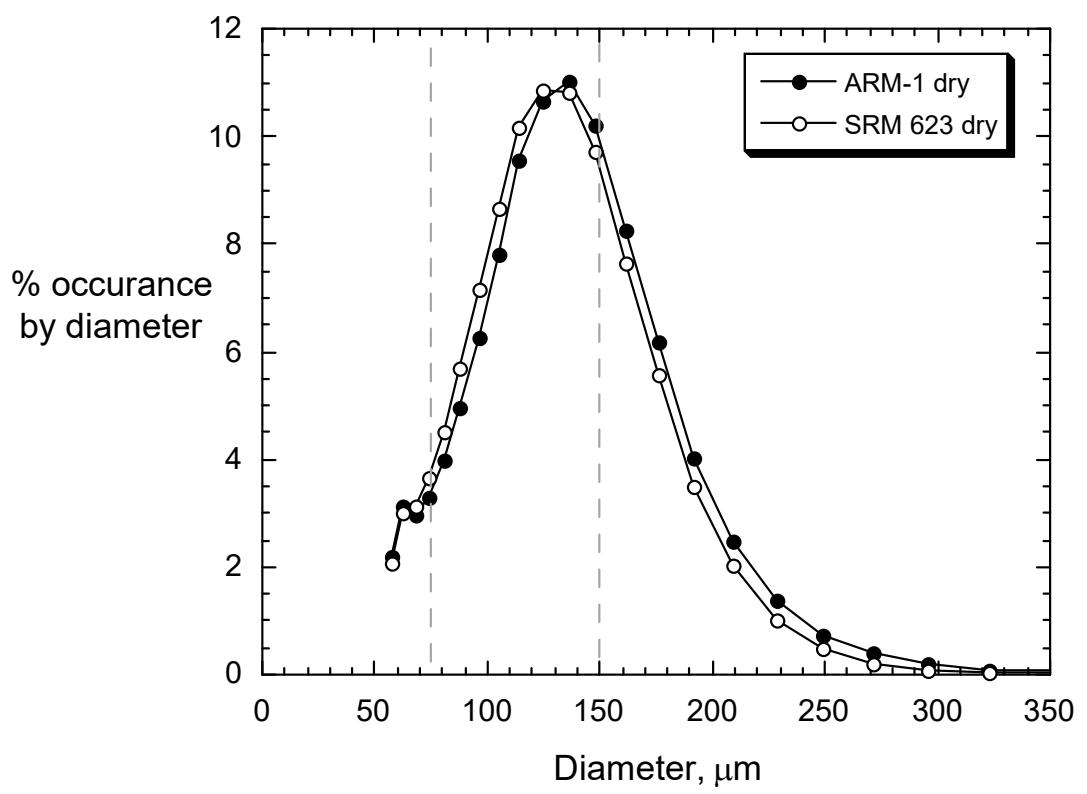

Figure 2. Measured particle size distributions of ARM-1 and SRM 623 glasses in $-100+200$ mesh size fractions. Vertical dashed lines indicate sieve opening sizes.

For spherical particles, the distribution of surface areas is proportional to the square of the diameter and the mean of the surface area occurs at a diameter smaller than the mean of the particle size distribution. Figure 3 shows the Microtrac results for $-100+200$ mesh size fraction of dry-sieved ARM-1 glass, a normal distribution representing those data, and the distribution of surface areas for spherical particles calculated based on the distribution of particle diameters. The distribution representing the occurrence of a particular diameter is

$\%$ occurence $=12 \exp \left[-\frac{(\text { diameter }-134)^{2}}{2 \times(42)^{2}}\right]$. 


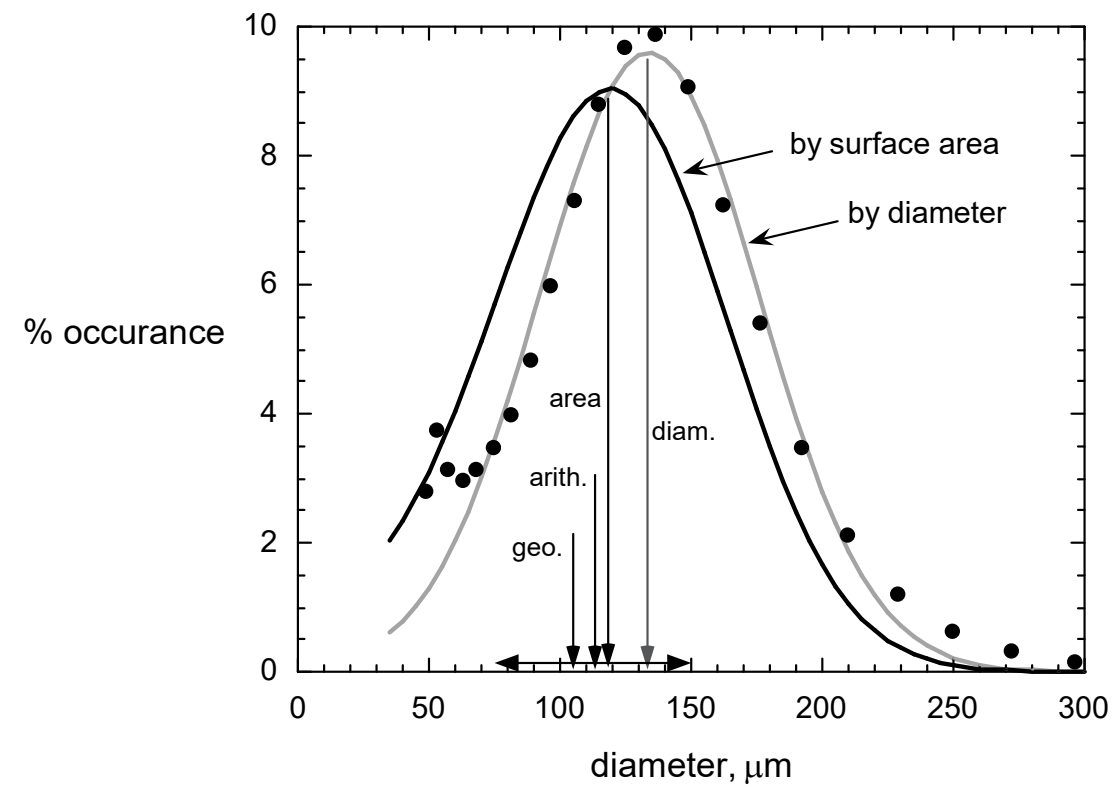

Figure 3. Normal distribution compared to Microtrac results for $-100+200$ mesh size fraction of drysieved ARM-1 glass and calculated distribution of areas for spherical particles.

The measured distribution (data points) is broadened slightly relative to the normal distribution (light curve), meaning there are slightly more of the smallest and largest particles than predicted by the normal distribution. The double-headed horizontal arrow in Figure 3 shows the range of sieve openings between about $75 \mu \mathrm{m}$ and $150 \mu \mathrm{m}$ and the vertical arrows identify (from left to right): geo. = geometric average of the sieve openings, arith $=$ arithmetic average of the sieve openings, area $=$ mean area and diam.$=$ the mean diameter of the particle distribution. Although the peak in the distribution of diameters (seen at diam. $\approx 132 \mu \mathrm{m}$ ) occurs at a significantly higher value than the average of the $-100+200$ mesh opening (seen at arith. $\approx 112 \mu \mathrm{m}$ ), the diameter corresponding to the peak in the distribution of areas (which occurs at area $\approx 119 \mu \mathrm{m}$ ) is well-represented by the average of the sieve sizes. That is, although the average mesh opening does not represent the mean value of the particle diameter very well, the surface area calculated with that value does represent the mean of the particle surface areas well. Particles with diameters less than $60 \mu \mathrm{m}$ represent about $2.5 \%$ of the total surface area in this modeled distribution, but it is likely that very few of these small particles are actually retained by the 200 mesh sieve and are present in the sample. Therefore, the mean surface area of the normal distribution is probably lower than the actual surface area because there are fewer small particles in the test sample than what is predicted by the distribution. 


\section{RESULTS}

The results reported by the five participants for triplicate PCT-A conducted with ARM-1 and SRM 623 glasses are summarized in Tables 2 and 3, respectively. Observing the ILS approach of anonymity, the participants are identified by letters (in random order). Normalized mass losses values $N L(i)$ were used to calculate the test precision rather than the measured concentrations to take into account differences in the exact amounts of glass and water used in each test. The normalized mass loss (in $\mathrm{g} \mathrm{m}^{-2}$ ) based on the solution concentration $\mathrm{C}(i)$ of species $i\left(\right.$ in $\left.\mathrm{g} \mathrm{mL}^{-1}\right)$ was calculated as

$$
N L(i)=\frac{C(i) \times V_{W}}{S_{s p} \times m_{G} \times f_{i}} .
$$

The $N L(i)$ values were calculated from the test data provided by the participants using the elemental mass fractions of species $i$ in the glass $f_{i}$ that are given in Table 1 . The surface area of glass in each test was calculated as the product of the mass of glass $m_{G}$ used in the test and the specific surface area $S_{s p}$ of the crushed glass. The specific surface areas for the $-100+200$ mesh size fractions are $0.0196 \mathrm{~m}^{2} / \mathrm{g}$ for ARM-1 glass $\left(\right.$ density $\left.=2.75 \mathrm{~g} \mathrm{~cm}^{-3}\right)$ and for SRM $623\left(\right.$ density $\left.=2.24 \mathrm{~g} \mathrm{~cm}^{-3}\right)$; these were calculated by modeling the particles as spheres with diameters equal to the average sieve opening. The solution volume $V_{W}$ (in $\mathrm{cm}^{3}$ ) was calculated from the mass of water used in the test and a density of $1.00 \mathrm{~g} \mathrm{~cm}^{-3}$. The glass surface area-to-solution volume $(\mathrm{S} / \mathrm{V})$ ratio is a characteristic test parameter that varies in PCT-A conducted with glasses having different densities. The $\mathrm{S} / \mathrm{V}$ ratio is often varied in PCT-B to affect the solution compositions that are generated.

The participants were asked to conduct blank tests without glass using the same amount of water and other test conditions as the PCT-A tests conducted with glass. The concentrations in all blank tests were negligible, but measured values were reported by some participants and detection limits were reported by others depending on the analytical method used. Because background adjustments could not be made consistently for all participants, the $N L(i)$ values were calculated without background corrections to avoid introducing bias.

The averages, standard deviations, and percent relative standard deviations are provided in Tables 2 and 3 for the triplicate tests with ARM-1 and SRM 623 glasses conducted by each participant. Note that the results of the third test conducted by Participant D with ARM-1 glass are shown as lined-out values because the relative masses of glass and water exceeded the acceptable range for PCT-A. That test was excluded and the reported average and standard deviation are for the two acceptable tests. The error was recognized by Participant D when the test was disassembled and the ILS lead was alerted. Participant D was advised (by WLE) to not repeat the test or set of tests, since this provided an opportunity to demonstrate the impact of a failed test on the analysis.

The pooled $N L(i)$ values based on the solution concentrations of $\mathrm{B}, \mathrm{Na}$, and $\mathrm{Si}$ are plotted in Figures $4 \mathrm{a}$ and $4 \mathrm{~b}$ for visual comparison. The horizontal dashed lines show the mean values of the pooled results. Values for $N L(B)$ and $N L(N a)$ are similar and significantly higher than the corresponding $N L(S i)$ values for tests with ARM-1 glass, whereas values for $N L(B)$ and $N L(S i)$ are similar and significantly lower than the corresponding $N L(N a)$ values for tests with SRM 623 glass. The relative values of $N L(B), N L(N a)$, and $N L(S i)$ differ both within and between tests conducted by the participants. Tests with ARM-1 glass conducted by Participants A, B, and C showed $N L(B)<N L(N a)$, whereas tests conducted by Participant D showed $N L(B)>N L(N a)$ and the results from Participant E were mixed. Tests with SRM 623 glass conducted by Participants $\mathrm{A}, \mathrm{B}$, and $\mathrm{C}$ showed $N L(B)<N L(S i)$, whereas tests by Participants $\mathrm{C}$, D, and $\mathrm{E}$ showed $N L(B)>N L(N a)$. 
Table 2. Results of PCT with ARM-1 Glass

\begin{tabular}{|c|c|c|c|c|c|c|c|c|c|c|c|c|c|}
\hline $\begin{array}{l}\text { Participant- } \\
\text { Test Number }\end{array}$ & $\begin{array}{c}\text { Mass } \\
\text { Glass, } \mathrm{g}\end{array}$ & $\begin{array}{c}\text { Mass } \\
\text { Water, g }\end{array}$ & $\begin{array}{c}\mathrm{w} / \mathrm{g} \\
\text { Ratio }\end{array}$ & $\begin{array}{l}\mathrm{S} / \mathrm{V} \\
\mathrm{m}^{-1}\end{array}$ & $\mathrm{pH}$ & $\begin{array}{l}{[\mathrm{Li}]} \\
\mathrm{mg} / \mathrm{L}\end{array}$ & $\begin{array}{l}{[\mathrm{B}]} \\
\mathrm{mg} / \mathrm{L}\end{array}$ & $\begin{array}{l}{[\mathrm{Na}],} \\
\mathrm{mg} / \mathrm{L}\end{array}$ & $\begin{array}{l}\text { [Si], } \\
\mathrm{mg} / \mathrm{L}\end{array}$ & $\begin{array}{c}\mathrm{NL}(\mathrm{Li}), \\
\mathrm{g} / \mathrm{m}^{2}\end{array}$ & $\begin{array}{l}\mathrm{NL}(\mathrm{B}), \\
\mathrm{g} / \mathrm{m}^{2}\end{array}$ & $\begin{array}{l}\mathrm{NL}(\mathrm{Na}), \\
\mathrm{g} / \mathrm{m}^{2}\end{array}$ & $\begin{array}{l}\mathrm{NL}(\mathrm{Si}), \\
\mathrm{g} / \mathrm{m}^{2}\end{array}$ \\
\hline A-1 & 1.01 & 10.10 & 10.00 & 2070 & $\mathrm{NR}^{\mathrm{a}}$ & 9.48 & 12.1 & 25.5 & 55.6 & 0.2056 & 0.1760 & 0.1821 & 0.1308 \\
\hline A-2 & 1.01 & 10.10 & 10.00 & 2070 & NR & 9.80 & 12.9 & 26.5 & 56.7 & 0.2123 & 0.1877 & 0.1889 & 0.1335 \\
\hline A-3 & 1.02 & 10.26 & 10.00 & 2058 & NR & 9.88 & 12.5 & 26.3 & 57.4 & 0.2155 & 0.1831 & 0.1886 & 0.1359 \\
\hline \multicolumn{6}{|c|}{ average } & 9.72 & 12.5 & 26.1 & 56.6 & 0.2111 & 0.1823 & 0.1865 & 0.1334 \\
\hline \multicolumn{6}{|c|}{ standard deviation } & 0.21 & 0.40 & 0.51 & 0.93 & 0.00506 & 0.00591 & 0.00388 & 0.00256 \\
\hline \multicolumn{6}{|c|}{ relative standard deviation } & $2.16 \%$ & $3.21 \%$ & $1.95 \%$ & $1.64 \%$ & $2.40 \%$ & $3.24 \%$ & $2.08 \%$ & $1.93 \%$ \\
\hline B-1 & 0.999 & 10.002 & 10.01 & 2067 & 10.33 & 11.3 & 13.6 & 30.8 & 57.5 & 0.2461 & 0.1982 & 0.2201 & 0.1355 \\
\hline B-2 & 1.001 & 10.002 & 9.99 & 2071 & 10.32 & 11.6 & 14.2 & 31.7 & 58.7 & 0.2511 & 0.2071 & 0.2259 & 0.1379 \\
\hline B-3 & 1.001 & 9.999 & 9.99 & 2072 & 10.26 & 11.8 & 14.6 & 32.2 & 59.1 & 0.2555 & 0.2121 & 0.2295 & 0.1390 \\
\hline \multicolumn{6}{|c|}{ average } & 11.6 & 14.1 & 31.6 & 58.4 & 0.2509 & 0.2058 & 0.2252 & 0.1375 \\
\hline \multicolumn{6}{|c|}{ standard deviation } & 0.23 & 0.50 & 0.70 & 0.82 & 0.00470 & 0.00703 & 0.00475 & 0.00176 \\
\hline \multicolumn{6}{|c|}{ relative standard deviation } & $1.99 \%$ & $3.54 \%$ & $2.22 \%$ & $1.40 \%$ & $1.87 \%$ & $3.42 \%$ & $2.11 \%$ & $1.29 \%$ \\
\hline $\mathrm{C}-1$ & 1.4932 & 14.9911 & 10.04 & 2062 & 10.15 & 13.4 & 16.9 & 36 & 64.2 & 0.2916 & 0.2473 & 0.2577 & 0.1517 \\
\hline $\mathrm{C}-2$ & 1.5055 & 15.0725 & 10.01 & 2067 & 10.11 & 13.1 & 15.8 & 34.9 & 63.2 & 0.2843 & 0.2306 & 0.2491 & 0.1489 \\
\hline $\mathrm{C}-3$ & 1.5029 & 15.0299 & 10.00 & 2070 & 10.13 & 12.6 & 15.9 & 33.3 & 61.2 & 0.2731 & 0.2318 & 0.2374 & 0.1440 \\
\hline \multicolumn{6}{|c|}{ average } & 13.03 & 16.20 & 34.7 & 62.9 & 0.2830 & 0.2366 & 0.2481 & 0.1482 \\
\hline \multicolumn{6}{|c|}{ standard deviation } & 0.40 & 0.61 & 1.36 & 1.53 & 0.00930 & 0.00934 & 0.01017 & 0.00387 \\
\hline \multicolumn{6}{|c|}{ relative standard deviation } & $3.07 \%$ & $3.77 \%$ & $3.92 \%$ & $2.43 \%$ & $3.29 \%$ & $3.95 \%$ & $4.10 \%$ & $2.63 \%$ \\
\hline D-1 & 1.5043 & 15.0142 & 9.98 & 2074 & NR & 13.4 & 23.4 & 41.6 & 58.7 & 0.2904 & 0.3412 & 0.2957 & 0.1379 \\
\hline $\mathrm{D}-2$ & 1.4989 & 15.0328 & 10.03 & 2064 & NR & 12.8 & 20.9 & 36.0 & 56.9 & 0.2789 & 0.3055 & 0.2572 & 0.1342 \\
\hline $\mathrm{D}-3^{\mathrm{b}}$ & 1.0026 & 14.9967 & 14.96 & 1384 & NR & 8.19 & 14.8 & 28.4 & 46.3 & 0.2654 & 0.3219 & 0.3032 & $\theta .1629$ \\
\hline \multicolumn{6}{|c|}{ average } & 13.1 & 22.2 & 38.8 & 57.8 & 0.2847 & 0.3233 & 0.2764 & 0.1361 \\
\hline \multicolumn{6}{|c|}{ standard deviation } & 0.42 & 1.81 & 3.94 & 1.30 & 0.00812 & 0.02524 & 0.02718 & 0.00260 \\
\hline \multicolumn{6}{|c|}{ relative standard deviation } & $3.20 \%$ & $8.16 \%$ & $10.17 \%$ & $2.25 \%$ & $3.20 \%$ & $8.04 \%$ & $9.94 \%$ & $1.92 \%$ \\
\hline E-1 & 1.00 & 10.02 & 10.02 & 2065 & 10.08 & 13.0 & 16.7 & 32.2 & 55.2 & 0.2816 & 0.2445 & 0.2303 & 0.1302 \\
\hline E-2 & 1.00 & 10.03 & 10.03 & 2064 & 10.09 & 12.2 & 15.6 & 31.9 & 53.8 & 0.2647 & 0.2277 & 0.2281 & 0.1269 \\
\hline E-3 & 1.00 & 10.03 & 10.03 & 2062 & 9.50 & 12.3 & 15.2 & 31.7 & 52.8 & 0.2679 & 0.2230 & 0.2268 & 0.1246 \\
\hline \multicolumn{6}{|c|}{ average } & 12.5 & 15.8 & 31.4 & 53.9 & 0.2714 & 0.2317 & 0.2284 & 0.1272 \\
\hline \multicolumn{6}{|c|}{ standard deviation } & 0.42 & 0.79 & 0.28 & 1.23 & 0.00897 & 0.01133 & 0.00180 & 0.00280 \\
\hline \multicolumn{6}{|c|}{ relative standard deviation } & $3.36 \%$ & $4.98 \%$ & $0.88 \%$ & $2.28 \%$ & $3.31 \%$ & $4.89 \%$ & $0.79 \%$ & $2.22 \%$ \\
\hline
\end{tabular}

${ }^{a}$ NR indicates that no value was reported by participant.

$\mathrm{b}$ These results excluded from average and standard deviation calculated for Lab D because value of w/g mass ratio exceeds the acceptable range. 
Table 3. Results of PCT with SRM 623 Glass

\begin{tabular}{|c|c|c|c|c|c|c|c|c|c|c|c|}
\hline $\begin{array}{l}\text { Participant - } \\
\text { Test Number }\end{array}$ & $\begin{array}{c}\text { Mass } \\
\text { Glass, g }\end{array}$ & $\begin{array}{c}\text { Mass } \\
\text { Water, g }\end{array}$ & $\begin{array}{l}\text { w/g } \\
\text { Ratio }\end{array}$ & $\begin{array}{l}\mathrm{S} / \mathrm{V} \\
\mathrm{m}^{-1}\end{array}$ & $\mathrm{pH}$ & $\begin{array}{l}{[\mathrm{B}]} \\
\mathrm{mg} / \mathrm{L}\end{array}$ & $\begin{array}{l}{[\mathrm{Na}]} \\
\mathrm{mg} / \mathrm{L}\end{array}$ & $\begin{array}{l}{[\mathrm{Si}]} \\
\mathrm{mg} / \mathrm{L}\end{array}$ & $\begin{array}{l}\mathrm{NL}(\mathrm{B}), \\
\mathrm{g} / \mathrm{m}^{2}\end{array}$ & $\begin{array}{l}\mathrm{NL}(\mathrm{Na}), \\
\mathrm{g} / \mathrm{m}^{2}\end{array}$ & $\begin{array}{c}\mathrm{NL}(\mathrm{Si}), \\
\mathrm{g} / \mathrm{m}^{2}\end{array}$ \\
\hline $\mathrm{A}-1$ & 1.04 & 10.43 & 10.03 & 2394 & $\mathrm{NR}^{\mathrm{a}}$ & 2.79 & 5.66 & 31.7 & 0.0351 & 0.0498 & 0.0388 \\
\hline A-2 & 1.05 & 10.52 & 10.02 & 2396 & NR & 2.91 & 6.00 & 33.1 & 0.0365 & 0.0527 & 0.0405 \\
\hline A-3 & 1.04 & 10.44 & 10.04 & 2392 & NR & 2.93 & 5.77 & 32.6 & 0.0369 & 0.0508 & 0.0400 \\
\hline \multirow{2}{*}{\multicolumn{6}{|c|}{$\begin{array}{r}\text { average } \\
\text { standard deviation }\end{array}$}} & 2.88 & 5.81 & 32.5 & 0.0362 & 0.0511 & 0.0398 \\
\hline & & & & & & 0.08 & 0.17 & 0.73 & 0.00098 & 0.00148 & 0.00088 \\
\hline \multicolumn{6}{|c|}{ relative standard deviation } & $2.78 \%$ & $2.93 \%$ & $2.25 \%$ & $2.70 \%$ & $2.90 \%$ & $2.21 \%$ \\
\hline B-1 & 1.001 & 10.000 & 9.99 & 2403 & 8.76 & 2.80 & 6.57 & 29.9 & 0.0351 & 0.0576 & 0.0364 \\
\hline B-2 & 1.001 & 10.001 & 9.99 & 2403 & 8.79 & 2.91 & 6.60 & 31.5 & 0.0364 & 0.0578 & 0.0384 \\
\hline B-3 & 1.000 & 10.002 & 10.00 & 2400 & 8.79 & 2.83 & 6.54 & 31.5 & 0.0355 & 0.0574 & 0.0384 \\
\hline \multicolumn{6}{|r|}{ average } & 2.85 & 6.57 & 31.0 & 0.0356 & 0.0576 & 0.0378 \\
\hline \multicolumn{6}{|c|}{ standard deviation } & 0.05 & 0.03 & 0.94 & 0.00068 & 0.00022 & 0.00116 \\
\hline \multicolumn{6}{|c|}{ relative standard deviation } & $1.75 \%$ & $0.46 \%$ & $3.04 \%$ & $1.90 \%$ & $0.39 \%$ & $3.07 \%$ \\
\hline $\mathrm{C}-1$ & 1.5060 & 15.0835 & 10.02 & 2397 & 8.65 & 3.26 & 6.12 & 32.2 & 0.0409 & 0.0538 & 0.0394 \\
\hline $\mathrm{C}-2$ & 1.5009 & 15.0766 & 10.05 & 2390 & 8.53 & 3.12 & 6.19 & 31.8 & 0.0393 & 0.0545 & 0.0390 \\
\hline $\mathrm{C}-3$ & 1.5029 & 15.0314 & 10.00 & 2401 & 8.60 & 3.24 & 5.99 & 32.5 & 0.0406 & 0.0526 & 0.0397 \\
\hline \multicolumn{6}{|c|}{ average } & 3.21 & 6.10 & 32.2 & 0.0403 & 0.0536 & 0.0393 \\
\hline \multicolumn{6}{|c|}{ standard deviation } & 0.08 & 0.10 & 0.35 & 0.00087 & 0.00100 & 0.00034 \\
\hline \multicolumn{6}{|c|}{ relative standard deviation } & $2.49 \%$ & $1.64 \%$ & $1.09 \%$ & $2.17 \%$ & $1.88 \%$ & $0.87 \%$ \\
\hline D-1 & 1.4999 & 14.9949 & 10.00 & 2402 & NR & 4.65 & 7.61 & 28.0 & 0.0583 & 0.0667 & 0.0341 \\
\hline D-2 & 1.503 & 15.006 & 9.98 & 2405 & NR & 4.28 & 6.04 & 26.4 & 0.0536 & 0.0529 & 0.0321 \\
\hline D-3 & 1.5036 & 15.0134 & 9.98 & 2405 & NR & 4.16 & 6.21 & 28.1 & 0.0520 & 0.0544 & 0.0343 \\
\hline \multicolumn{6}{|c|}{ average } & 4.36 & 6.62 & 27.5 & 0.0547 & 0.0580 & 0.0335 \\
\hline \multicolumn{6}{|c|}{ standard deviation } & 0.26 & 0.86 & 0.98 & 0.00328 & 0.00758 & 0.00121 \\
\hline \multicolumn{6}{|c|}{ relative standard deviation } & $5.96 \%$ & $12.99 \%$ & $3.57 \%$ & $6.99 \%$ & $13.88 \%$ & $3.63 \%$ \\
\hline E-1 & 1.00 & 9.99 & 9.99 & 2403 & 7.58 & 3.69 & 6.78 & 34.0 & 0.0462 & 0.0594 & 0.0415 \\
\hline E-2 & 1.00 & 9.98 & 9.98 & 2405 & 7.47 & 3.86 & 6.99 & 35.7 & 0.0483 & 0.0612 & 0.0435 \\
\hline E-3 & 1.00 & 10.04 & 10.04 & 2392 & 8.64 & 3.72 & 7.55 & 35.2 & 0.0468 & 0.0664 & 0.0432 \\
\hline \multicolumn{6}{|c|}{ average } & 3.76 & 7.10 & 35.0 & 0.0471 & 0.0623 & 0.0427 \\
\hline \multicolumn{6}{|c|}{ standard deviation } & 0.09 & 0.40 & 0.86 & 0.00110 & 0.00366 & 0.00107 \\
\hline \multicolumn{6}{|c|}{ relative standard deviation } & $2.39 \%$ & $5.63 \%$ & $2.46 \%$ & $2.34 \%$ & $5.89 \%$ & $2.51 \%$ \\
\hline
\end{tabular}

${ }^{a} \mathrm{NR}$ indicates that no value was reported by participant. 


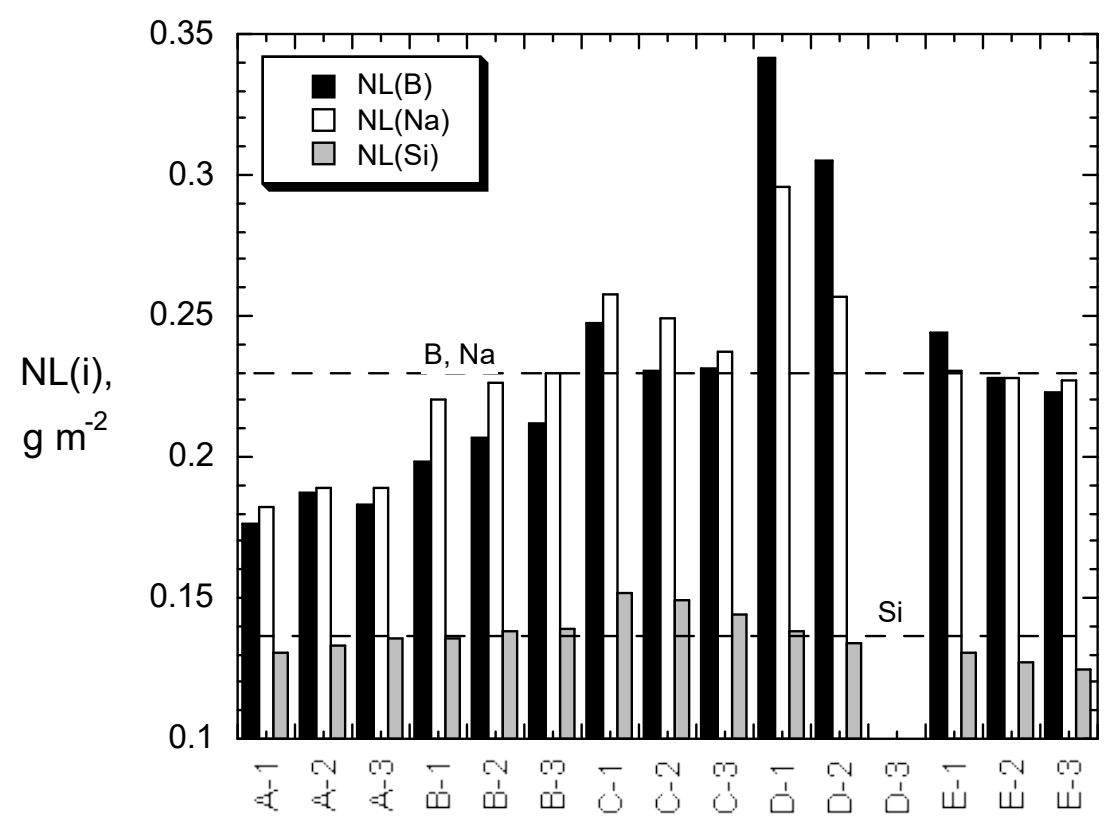

Participant

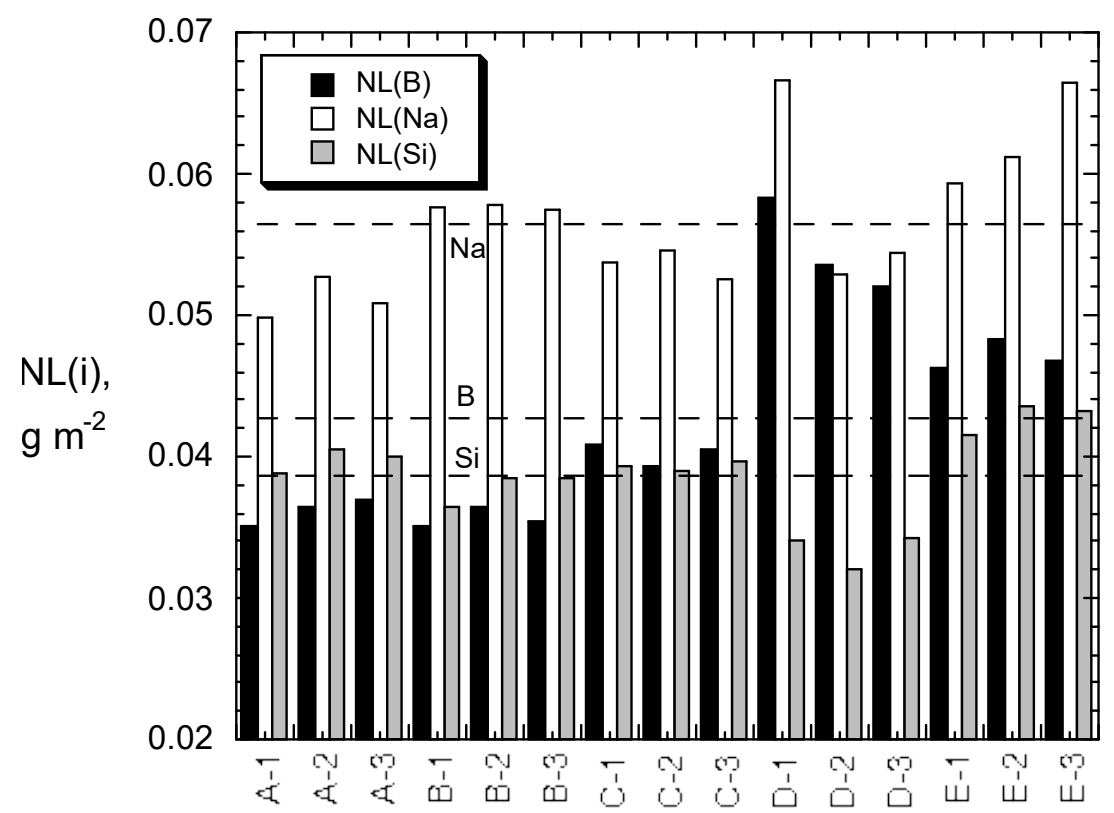

Participant

Figure 4. Individual $N L(B), N L(N a)$, and $N L(S i)$ values for tests with (a) ARM-1 glass and (b) SRM 623 glass. The horizontal dashed lines show the mean values of the pooled results. 


\subsection{Statistical Analysis of ILS Results}

Statistical analyses of the measured values are summarized in the following equations. The average of the responses $x_{p}$ measured by each participant $p$ in $n$ replicate tests is

$\bar{x}_{p}=\sum x_{p} / n$

and the standard deviation for the results of replicate tests by participant $p$ is

$s_{p}=\left[\left(\sum\left(x_{p}-\bar{x}_{p}\right)^{2}\right) /(n-1)\right]^{1 / 2}$.

This is a measure of the within-laboratory (intralaboratory) precision. Values of $\bar{x}_{p}$ and $s_{p}$ are included as the average and standard deviation values that are given for each participant in Tables 2 and 3 . The consensus average for the $p$ participants is

$\bar{x}=\sum \bar{x}_{P} / p$.

The standard deviation of the averages for replicate tests by the same participant from the consensus average is

$s_{x}=\left[\left(\sum\left(\bar{x}_{p}-\bar{x}\right)^{2}\right) /(p-1)\right]^{1 / 2}$.

The standard deviation for the normal distribution of laboratory means is

$s_{L}=\left(s_{\bar{x}}^{2}+\left(s_{r}^{2} / n\right)\right)^{1 / 2}$.

The pooled within-laboratory (intralaboratory) standard deviation is

$s_{r}=\left[\sum s_{p}^{2} / p\right]^{1 / 2}$.

This gives the estimated standard deviation for repeatability of measurements made within a single laboratory. The between-laboratory (interlaboratory) estimate of precision is

$s_{R}=\left(s_{\bar{x}}^{2}+s_{r}^{2}(n-1) / n\right)^{1 / 2}$.

This is the reproducibility standard deviation. Smaller values of the standard deviation represent higher test precision.

Two other expressions are used to quantify the repeatability and reproducibility of the tests:

- $\quad$ The estimated $95 \%$ repeatability level is $\mathrm{I}(\mathrm{r})=2.83 \cdot \mathrm{S}_{\mathrm{r}}$. On the basis of test error alone, the absolute value of the difference of two test results obtained in the same laboratory will exceed I(r) only approximately $5 \%$ of the time.

- $\quad$ The estimated $95 \%$ reproducibility level is $\mathrm{I}(\mathrm{R})=2.83 \cdot \mathrm{S}_{\mathrm{R}}$. On the basis of test error alone (including within- and between-laboratory components), the absolute value of the difference between two test results obtained in different laboratories will exceed I(R) only approximately $5 \%$ of the time. 
The precision statistics for the PCT-A ILS with ARM-1 and SRM 623 glasses are summarized in Table 4. Values for NL(B) and NL(Na) are given for statistics including and excluding results from Lab D. As discussed below, the results of Lab D were within the acceptable range of mean values for between-laboratory precision, but the within-laboratory precision based on NL(B) and NL(Na) exceeded the acceptable range. Whether the Lab D results are included or not has little effect on the mean value, but almost doubles the repeatability levels. The values of $\bar{x}_{p}$ and $s_{p}$ for each participant are given in Tables 2 and 3 and plotted in Figure 5. The results show the within-laboratory imprecision (the uncertainty bars) to be well within the range of between-laboratory values (the bar heights).

Table 4. Summary of Precision Statistics for PCT-A Tests ${ }^{\mathrm{a}}$

\begin{tabular}{|c|c|c|c|c|c|c|c|}
\hline & $\bar{x}_{p}$ & $s_{r}$ & $S_{\bar{x}}$ & $s_{L}$ & $s_{R}$ & $\mathrm{I}(\mathrm{r})$ & $\mathrm{I}(\mathrm{R})$ \\
\hline \multicolumn{8}{|l|}{ ARM-1 } \\
\hline $\mathrm{NL}(\mathrm{Li})^{\mathrm{b}}$ & 0.260 & 0.00749 & 0.0604 & 0.0607 & 0.0602 & 0.0212 & 0.172 \\
\hline $\mathrm{NL}(\mathrm{B})^{\mathrm{b}}$ & 0.236 & 0.0137 & 0.107 & 0.107 & 0.107 & 0.0387 & 0.304 \\
\hline $\mathrm{NL}(\mathrm{Na})^{\mathrm{b}}$ & 0.233 & 0.0133 & 0.0659 & 0.0668 & 0.0654 & 0.0376 & 0.189 \\
\hline $\mathrm{NL}(\mathrm{Na})^{\mathrm{c}}$ & 0.222 & 0.006 & 0.044 & 0.045 & 0.0442 & 0.0170 & 0.126 \\
\hline $\mathrm{NL}(\mathrm{Si})^{\mathrm{b}}$ & 0.136 & 0.00280 & 0.0130 & 0.0132 & 0.0129 & 0.00792 & 0.0374 \\
\hline \multicolumn{8}{|l|}{ SRM 623} \\
\hline $\mathrm{NL}(\mathrm{B})^{\mathrm{b}}$ & 0.0428 & 0.00168 & 0.0157 & 0.0158 & 0.0157 & 0.00476 & 0.0446 \\
\hline $\mathrm{NL}(\mathrm{B})^{\mathrm{c}}$ & 0.0398 & 0.0009 & 0.0070 & 0.0070 & 0.0069 & 0.00260 & 0.0198 \\
\hline $\mathrm{NL}(\mathrm{Na})^{\mathrm{b}}$ & 0.0565 & 0.00385 & 0.00704 & 0.00771 & 0.00668 & 0.0109 & 0.0218 \\
\hline $\mathrm{NL}(\mathrm{Na})^{\mathrm{c}}$ & 0.0562 & 0.0020 & 0.0068 & 0.0070 & 0.0067 & 0.00577 & 0.0199 \\
\hline $\mathrm{NL}(\mathrm{Si})^{\mathrm{b}}$ & 0.0386 & 0.00098 & 0.00574 & 0.00580 & 0.00571 & 0.00278 & 0.0164 \\
\hline
\end{tabular}

${ }^{\text {a }}$ Symbols defined in text.

${ }^{\mathrm{b}}$ Including Lab D results.

${ }^{c}$ Excluding Lab D results.

\subsection{Consistency of ILS results}

A one-way analysis of variance was used to evaluate the within-laboratory and between-laboratory test precision quantitatively. These analyses indicate whether the data provide a sufficiently consistent measure of the test method and provide values of statistical precision. They also identify inconsistent data that should be investigated by the participants. In the ILS, the repeatability represents the variability between test results obtained within a single laboratory by a single operator with a specific test apparatus using test specimens taken at random from the single quantity of homogeneous material prepared for use in the study. Reproducibility represents the variability between test results obtained by researchers in different laboratories using test specimens taken at random from the common source material prepared for the study. The statistical parameters in Table 4 were used to determine the repeatability (the withinlaboratory consistency) and the reproducibility (the between-laboratory consistency) that can be expected for PCTs. Variations due to sample preparation effects, including particle shape and size distributions, will add to the between-laboratory imprecision but is not expected to affect the withinlaboratory test consistency. Those effects are expected to be negligible in this study. 


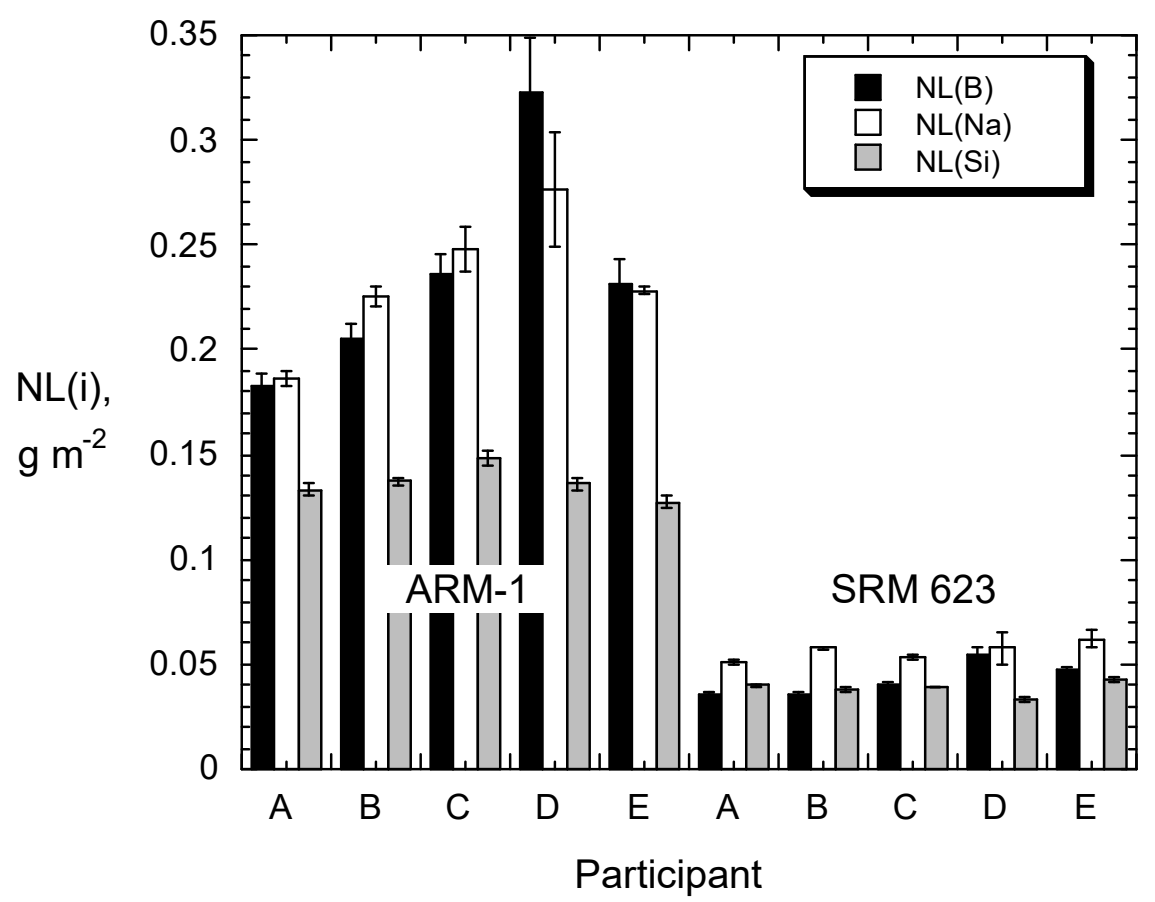

Figure 5. Mean values of $N L(B), N L(N a)$, and $N L(S i)$ for PCT-A tests with ARM-1 and SRM 623 glasses. Uncertainty bars show mean \pm 1 standard deviation.

The between-laboratory consistency is conveniently determined by the $h$-consistency statistic, which is defined as the difference between the value measured by a participant $\left(\bar{x}_{p}\right)$ and the consensus value $(\bar{x})$ divided by the standard deviation of the averages $\left(s_{\bar{x}}\right)$ :

$h=\frac{\left(\bar{x}_{p}-\bar{x}\right)}{s_{\bar{x}}}$

The $h$-consistency statistic is unitless and can be used to evaluate the overall variability of the analyses among the participants and to compare the results from one participant to the results from all the other participants. At the $0.5 \%$ significance level, the critical values of $h$ for 5 participants are \pm 1.74 (see Table 5 in [4]). The critical value was provided to aid in the decision of whether or not the deviation in the results of a particular laboratory exceeds that expected due to random error and warrants investigation. We used the critical value to identify results to be excluded from the calculations of consensus values and the test precision.

The within-laboratory consistency is determined by the $k$-consistency statistic, which is defined as the standard deviation for a participant $\left(\mathrm{s}_{\mathrm{p}}\right)$ divided by the repeatability standard deviation $\left(\mathrm{s}_{\mathrm{r}}\right)$ :

$k=\frac{s_{p}}{s_{r}}$

The $k$-consistency statistic provides a measure of how the variability within a laboratory compares with the combined variability of all laboratories. The $k$-value is unitless. The critical $k$-value for an ILS with 
five participants conducting triplicate tests is 1.92 (ASTM 2015b). Note that a very small $k$-consistency parameter value indicates a less sensitive measurement scale compared with the other laboratories, which may also warrant investigation.

The $h$-consistency and $k$-consistency values are summarized in Table 5 and plotted in Figures $6 \mathrm{a}$ and $6 \mathrm{~b}$, respectively. Examination of Figure 6a shows that the $h$-values for all measurements are within the critical values. Examination of Figure $6 \mathrm{~b}$ shows that the $k$-values are exceeded by the Na concentration measured in tests with ARM-1 glass and by the B and Na concentrations measured in tests with SRM 623 glass conducted by Participant D. This finding means that the variation in the results for replicate tests conducted by Participant D is inconsistent with (higher than) that for tests conducted by the other participants. The imprecision may be related to the test execution or the solution analysis. Both the B and Na results for SRM 623 glass by Participant D exceed the critical $k$-value of 1.92 for triplicate tests and are excluded from the calculated precision. In the case of tests with ARM-1 glass, the comparison is biased by the fact that results for only two rather than three replicate tests were used to determine the $k$-value. We note that the $k$-value for $\mathrm{Na}$ in tests with ARM-1 glass falls below critical $k$-value of 2.06 for duplicate tests conducted by five participants. Nevertheless, these values are excluded from the precision determined in the ILS for triplicate tests. Test results for which $k$-values exceeded the critical value were excluded from the calculations that are reported in Table 4.

TABLE 5 Summary of $h$-Consistency and $k$-Consistency Values

\begin{tabular}{|c|c|c|c|c|c|c|c|c|}
\hline \multirow{2}{*}{ Value } & \multirow{2}{*}{ Participant } & \multirow{2}{*}{$\begin{array}{r}\text { NL(Li) } \\
\text { ARM-1 }\end{array}$} & \multicolumn{2}{|c|}{ NL(B) } & \multicolumn{2}{|c|}{$\mathrm{NL}(\mathrm{Na})$} & \multicolumn{2}{|c|}{ NL(Si) } \\
\hline & & & ARM-1 & SRM 623 & ARM-1 & SRM 623 & ARM-1 & SRM 623 \\
\hline \multirow{5}{*}{$h$} & $\mathrm{~A}$ & -0.784 & -0.444 & -0.509 & -0.657 & -0.734 & -0.241 & 0.201 \\
\hline & $\mathrm{B}$ & -0.125 & -0.223 & -0.561 & -0.0709 & 0.260 & 0.076 & -0.140 \\
\hline & $\mathrm{C}$ & 0.406 & 0.064 & -0.0959 & 0.277 & -0.350 & 0.898 & 0.130 \\
\hline & $\mathrm{D}$ & 0.434 & 0.876 & 0.575 & 0.708 & -0.165 & -0.033 & -0.894 \\
\hline & $\mathrm{E}$ & 0.214 & 0.0190 & 0.590 & -0.0214 & 0.989 & -0.711 & 0.703 \\
\hline \multirow{5}{*}{$k$} & A & 0.676 & 0.432 & 0.580 & 0.292 & 0.384 & 0.913 & 0.894 \\
\hline & B & 0.628 & 0.514 & 0.403 & 0.358 & 0.0579 & 0.630 & 1.18 \\
\hline & $\mathrm{C}$ & 1.24 & 0.682 & 0.520 & 0.765 & 0.260 & 1.382 & 0.349 \\
\hline & $\mathrm{D}$ & 1.08 & 1.84 & 1.95 & 2.04 & 1.97 & 0.927 & 1.23 \\
\hline & $\mathrm{E}$ & 1.20 & 0.828 & 0.654 & 0.135 & 0.950 & 1.00 & 1.09 \\
\hline
\end{tabular}

The expected values for PCTs conducted with a particular reference glass are given by consensus values $I(\mathrm{r})$ for repeatability and $I(\mathrm{R})$ for reproducibility. Two values measured at the same laboratory differing by more than the value of $I(\mathrm{r})$ should be considered suspect. Likewise, two values measured at different laboratories differing by more than the value of $I(\mathrm{R})$ should be considered suspect. The expected repeatability and reproducibility of a PCT-A test are included in Table 4, which gives the expected values for PCT-A tests conducted with ARM-1 and SRM 623 glasses washed to remove fines. These are given in terms of the normalized mass loss values rather than the measured concentrations to take variations in the w/g mass ratio allowed within PCT-A (10.0 \pm 0.5$)$ into account. The effects of other variations that are within the ranges allowed in the PCT-A method, such as the test temperature $\left(90 \pm 2{ }^{\circ} \mathrm{C}\right)$, are not explicit in the test precision but are expected to be represented by the value of the interlaboratory precision (reproducibility) due to a likely range of actual oven temperatures used in tests by the five participants. They are also expected to represent the precision with which PCT-B tests are conducted with test parameter values outside the restricted ranges of those specified for PCT-A. 

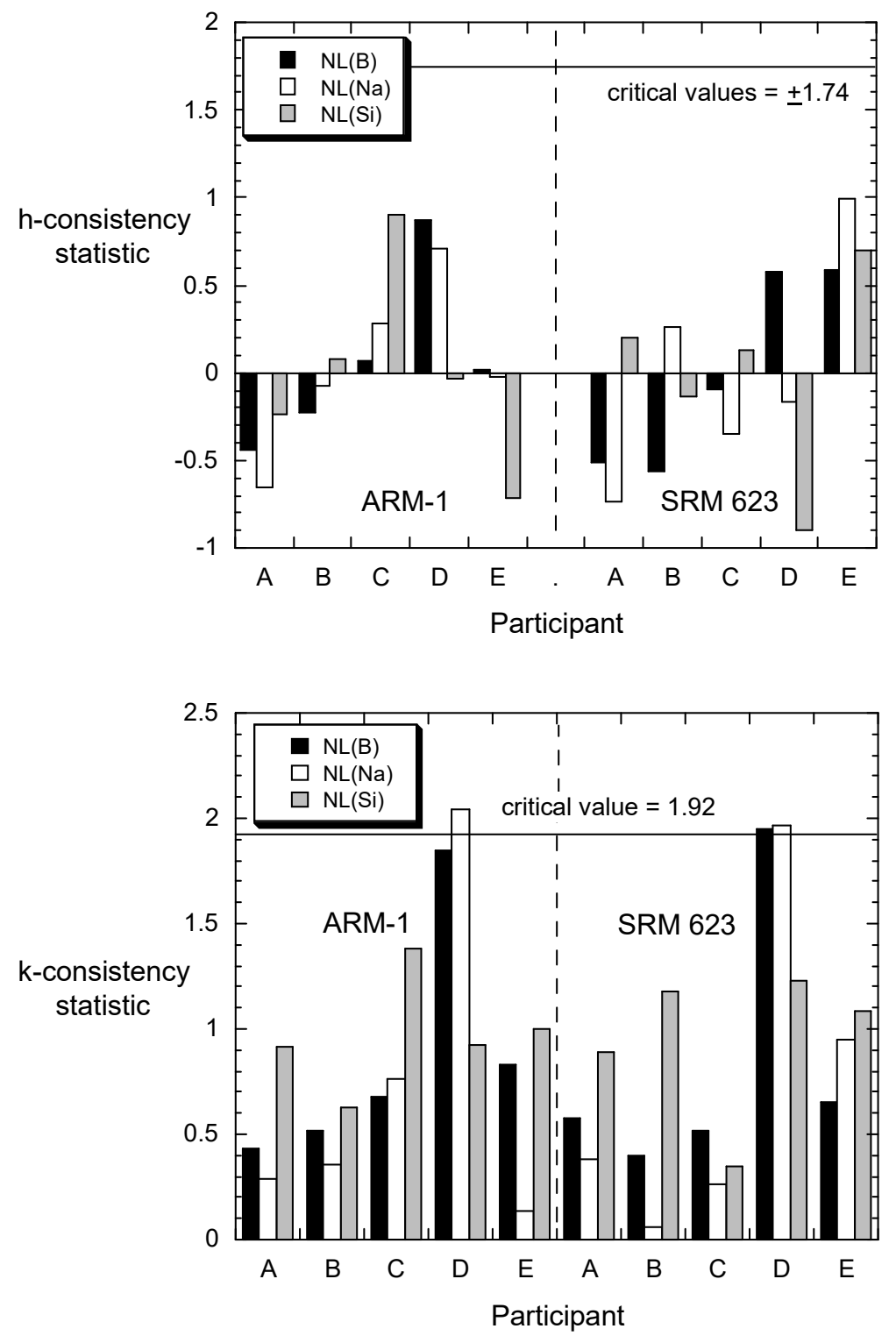

Figure 6. Values of (a) $h$-statistic and (b) $k$-statistic for PCT-A tests with ARM-1 and SRM 623 glasses. 


\section{DISCUSSION}

\section{Effects of Fines}

A previous ILS was conducted during 1989 (referred to herein as ILS-1989) to measure the precision of PCT-A with ARM-1 and SRM 623 glasses in which the glasses were not treated to remove fines generated during crushing before testing [5]. The results of the present study (referred to as ILS-2014) are compared with the results of that study to assess the effects of fines on the test response and precision. Only the mean values and relative standard deviations of the concentrations were reported for ILS-1989 and those values were used to back-calculate the standard deviations for comparison with results from ILS-2014. As noted above, direct comparison of the concentrations does not take into account differences in the relative masses of glass and water used in each test and does not provide an accurate measure of the test precision. However, it does provide a qualitative indication of the effects of fines on the test response and variance. Note that the w/g mass ratios of tests conducted in ILS-1989 ranged from 9.99 to 10.05 except for tests conducted by Lab 2, which were run at $\mathrm{w} / \mathrm{g}$ mass ratios between 10.00 and 11.01. The solution concentrations in tests by Lab 2 were identified as outliers in reference [5], but it was not mentioned that the too-high w/g mass ratio was the obvious reason for that deviation. The too-high $\mathrm{w} / \mathrm{g}$ mass ratio (which provided a too-low $\mathrm{S} / \mathrm{V}$ ratio) resulted in a higher glass dissolution rate and higher concentrations in those tests. Therefore, only the statistics provided in reference [5] for ILS-1989 that excluded the Lab 2 results were compared with the ILS-2014 results.

Table 6 provides a comparison of the results from ILS-2014 conducted using glass without fines and the results from ILS-1989 conducted using glass with fines (excluding Lab 2 results). The consensus mean and standard deviation values from the two ILS are plotted in Figure 7. The results show the fines have a significant impact on the test response (mean values represented by the bar heights), but do not have a significant effect on the test precision that is quantified by the standard deviations (represented by the uncertainty bars in Figure 7). Implicit in the statistical evaluations provided in reference [5] is the assumption that the volumes of fines present in all tests were in the same proportion to the mass of glass. This is reasonable because samples from the same source glasses were used in all tests. Significant differences in the amounts of fines present in different tests would be expected to impact both the mean and standard deviation values.

TABLE 6 Effects of fines on PCT-A response, concentrations in $\mathrm{mg} \mathrm{L}^{-1}$

\begin{tabular}{lccccccc}
\hline \multirow{2}{*}{ Glass } & \multirow{2}{*}{ Analyte } & \multicolumn{2}{c}{ ILS-1989 Glass with fines ${ }^{\mathrm{a}}$} & \multicolumn{2}{c}{ ILS-2014 Glass without fines } \\
\cline { 2 - 7 } & & mean & std. dev. & \%rsd & mean & std. dev. & \%rsd \\
\hline \multirow{3}{*}{ ARM-1 } & $\mathrm{Li}$ & 21.73 & 1.17 & 5.40 & 11.91 & 1.94 & 16.3 \\
& $\mathrm{~B}$ & 27.49 & 2.07 & 7.52 & 15.74 & 4.52 & 28.7 \\
& $\mathrm{Na}$ & 55.65 & 4.16 & 7.47 & 32.19 & 3.83 & 11.9 \\
& $\mathrm{Si}$ & 80.16 & 3.92 & 4.89 & 57.92 & 3.66 & 6.32 \\
\hline \multirow{3}{*}{ SRM 623 } & $\mathrm{B}$ & 7.05 & 0.50 & 7.04 & 3.41 & 0.48 & 14.2 \\
& $\mathrm{Na}$ & 12.74 & 0.87 & 6.81 & 6.44 & 0.54 & 8.40 \\
& $\mathrm{Si}$ & 46.10 & 3.72 & 8.06 & 31.61 & 2.90 & 9.19 \\
\hline
\end{tabular}

${ }^{a}$ Results from reference [5].

${ }^{\mathrm{b}}$ Results from this study. 


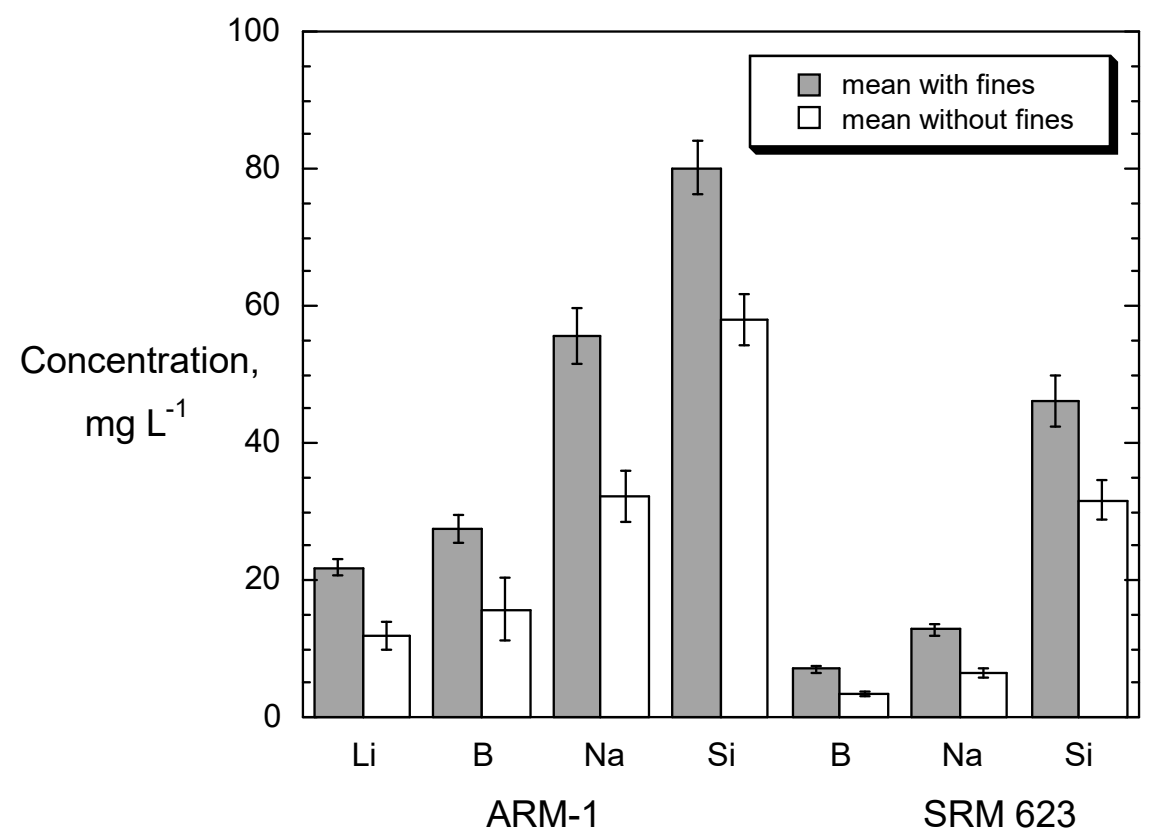

Figure 7. Consensus mean and reproducibility standard deviation values from ILS-1989 conducted using glass with fines (filled bars) and ILS-2014 conducted using glass without fines (open bars).

We note the similarity of the ratios of the concentrations of readily-released glass constituents $\mathrm{B}$ and $\mathrm{Na}$ in tests with and without fines for each glass (both are about 1.7 for ARM-1 glass and both about 2.1 for SRM 623 glass), and that those ratios are higher than the ratios for Si (about 1.4 for both glasses). This is probably because the release of Si slows as the dissolved Si concentration increases due to decreasing reaction affinity for silica hydrolysis, whereas the release rates of $\mathrm{B}, \mathrm{Li}$, and $\mathrm{Na}$ are not significantly affected by their dissolved concentrations.

\section{Standard Deviation and Relative Standard Deviation}

The standard deviations of the $\mathrm{B}, \mathrm{Na}$, and $\mathrm{Si}$ concentrations are similar in tests conducted using glasses without or with fines, although the mean concentrations are lower in tests using glasses without fines. The much lower \%rsd values for tests using glasses with fines is an artifact of the higher solution concentrations generated due to the dissolution of fines and does not reflect the test precision. The higher concentrations generated by the dissolution of fines has another effect on the test precision: the higher concentrations of dissolved silica slow subsequent glass dissolution and decrease the contribution of glass particle dissolution to the test response and the effects of test execution. That is, the test responses are dominated by the uncontrolled (and unknown) amounts of fines that dissolve rather than by dissolution of the sized glass particles under the controlled test conditions.

The percent relative standard deviation is the ratio of the mean concentration and standard deviation and the value will vary with the mean concentrations. The nearly factor-of-two lower concentration values generated in tests using glasses without fines effectively doubles the relative standard deviation compared to that for tests using glasses with fines. Likewise, PCT-B tests that are conducted for longer durations, at higher glass-to-water mass ratios, or with smaller size fractions of crushed glass will generate higher solution concentrations and have lower percent relative standard deviation values than those measured under the PCT-A test conditions. Lower relative standard deviation values only indicate that the test uncertainty is a smaller fraction of the test response, not better test precision. 


\section{Solution Analyses}

The ASTM C1285 test method calls for the analysis of a standard solution prior to analysis of the test solutions (Steps 21.4.15 and 24.4.14). Uncertainty in the solution analysis is lumped with the overall precision of the triplicate tests conducted by a laboratory and not considered separately. The ILS-1989 documented in reference [5] included double blind triplicate analyses of a standard solution that was provided to all participants to distinguish between the relative contributions of test execution and analysis of the test solutions to the overall precision. Since the analytical precision will vary with the analyte concentrations, the composition of the standard solution was similar to that generated during the test. The analytical precision, expressed as percent relative standard deviation, for the analytes of primary concern in PCTs with waste glasses are $\mathrm{Li}=1.58 \%, \mathrm{~B}=2.38 \%, \mathrm{Na}=1.42 \%$, and $\mathrm{Si}=2.20 \%$. This analytical variability is expected to be representative of similar solutions and establish a similar limiting precision for all PCTs, including those in ILS-2014. Comparing these values with the overall standard deviations summarized in Table 6 indicates the uncertainty in the solution analysis dominated the variance within the PCT results in both studies. The analytical precision can be improved indirectly by averaging more replicate analyses. 


\section{CONCLUSIONS}

The results of an ILS for ASTM C1285 Method A tests with reference ARM-1 and SRM 623 glasses that was conducted in 2014 (ILS-2014) were used to determine the precision with which tests can be conducted using specified parameter values. Glass provided from a common source was used in the study to exclude variance due to preparation of the crushed glass used in the tests. The test response is quantified using concentrations of the major analytes $\mathrm{B}, \mathrm{Na}$, and $\mathrm{Si}$ and the test precision varies in proportion to their concentrations in the test solution. The Si concentration is highest and is usually measured with the greatest precision. However, comparing responses based on all three elements provides insights into the dissolution behavior. The test precision is best evaluated using the normalized elemental mass loss to take differences in the w/g mass ratios used in different tests and the different amounts of $\mathrm{B}, \mathrm{Na}$, and $\mathrm{Si}$ in different glasses into account for direct comparisons.

The deviations in the results of the five participants from the mean responses did not correlate with their experience in performing PCTs, which indicates the instructions provided in the ASTM C1285 test procedure are sufficiently clear for a new user to conduct tests successfully.

Comparisons with the results of a previous ILS in which the same glasses and test conditions were used but the glasses were not washed to remove fines (ILS-1989) prior to testing shows that the presence of fines greatly increases the test response (i.e., the dissolved concentrations), but does not affect the precision with which the test can be performed. The test precision is limited by the analytical uncertainty in measuring the dissolved concentrations. This comparison shows how using the relative standard deviation to represent the test precision can be misleading, and that the mean response and standard deviation should be considered individually when evaluating the test precision.

Because all participants used test parameter values near the mean values specified in ASTM C1285, the results of ILS-2014 provide a measure of the best achievable precision of responses for tests conducted using parameter values that are more tightly constrained than the ranges specified in the procedure. Slightly poorer precision than what was achieved in the ILS-2014 should be expected for tests conducted with parameter values that vary within the ranges permitted in the procedure. That is, the test response is sensitive to variations in test parameter values within the ranges specified in the procedure. 


\section{References}

[1] Standard Test Methods for Determining Chemical Durability of Nuclear Waste Glasses: The Product Consistency Test (PCT). Standard C1285-14, Annual Book of ASTM Standards Vol. 12.01, ASTMInternational, West Conshohocken, PA (2019).

[2] Barkatt, Aa., Barkatt, A., Pehrsson, P.E., Szoke, P., and Macedo, P.B. (1981). "Static and Dynamic Tests for the Chemical Durability of Nuclear Waste Glass," Nuclear and Chemical Waste Management, 2, 151-164.

[3] Ebert, W.L. (2006). Comparison of the Results of Short-Term Static Tests and Single-Pass Flow-Through Tests with LRM Glass. Argonne National Laboratory report ANL-06/51.

[4] Standard Practice for Conducting an Interlaboratory Study to Determine the Precision of a Test Method. Standard E691-19, Annual Book of ASTM Standards Vol. 14.05, ASTM-International, West Conshohocken, PA (2019).

[5] Piepel, G.F., Jones, T.E., Eggett, D.L., and Mellinger, G.B. (1989). Product Consistency Test Round Robin Conducted by the Materials Characterization Center-Summary Report. Pacific Northwest Laboratory report PNL-6967. 


\section{Argonne}

Chemical and Fuel Cycle Technologies Division

Argonne National Laboratory

9700 South Cass Avenue, Bldg. 205

Argonne, IL 60439

www.anl.gov

Argonne National Laboratory is a U.S. Department of Energy laboratory managed by UChicago Argonne, LL 